\title{
ADDRESSING THE LIMIT OF DETECTABILITY OF RESIDUAL OXIDE DISCONTINUITIES IN FRICTION STIR BUTT WELDS OF ALUMINUM USING PHASED ARRAY ULTRASOUND
}

\author{
P. H. Johnston
}

NASA Langley Research Center, Hampton, VA 23681

\begin{abstract}
This activity seeks to estimate a theoretical upper bound of detectability for a layer of oxide embedded in a friction stir weld in aluminum. The oxide is theoretically modeled as an ideal planar layer of aluminum oxide, oriented normal to an interrogating ultrasound beam. Experimentally-measured grain scattering level is used to represent the practical noise floor. Echoes from naturally-occurring oxides will necessarily fall below this theoretical limit, and must be above the measurement noise to be potentially detectable.
\end{abstract}

Keywords: Ultrasonic NDE, Friction Stir Weld, Residual Oxide Discontinuity

PACS: 43.35.Zc

\section{INTRODUCTION}

The National Aeronautics and Space Administration (NASA) is developing the Ares 1 launch vehicle to place the Orion space capsule into orbit, as part of the Constellation Program. The Upper Stage of the Ares 1, depicted in Fig. 1, will be fabricated from aluminum and aluminum-lithium alloys, which will be joined by the relatively new friction stir weld (FSW) process. One of the conditions which may occur in a FSW is a residual oxide discontinuity (ROD), which can weaken the weld. Phased array ultrasonic testing (PAUT) is a leading candidate for selection for the NDE of the Ares 1 welds. However, several different groups have been evaluating PAUT for use on FSW, and there have been conflicting reports on the detection of ROD. This paper results from an effort to establish an estimate of the theoretical upper bound on the potential detectability of ROD in aluminum FSW. 


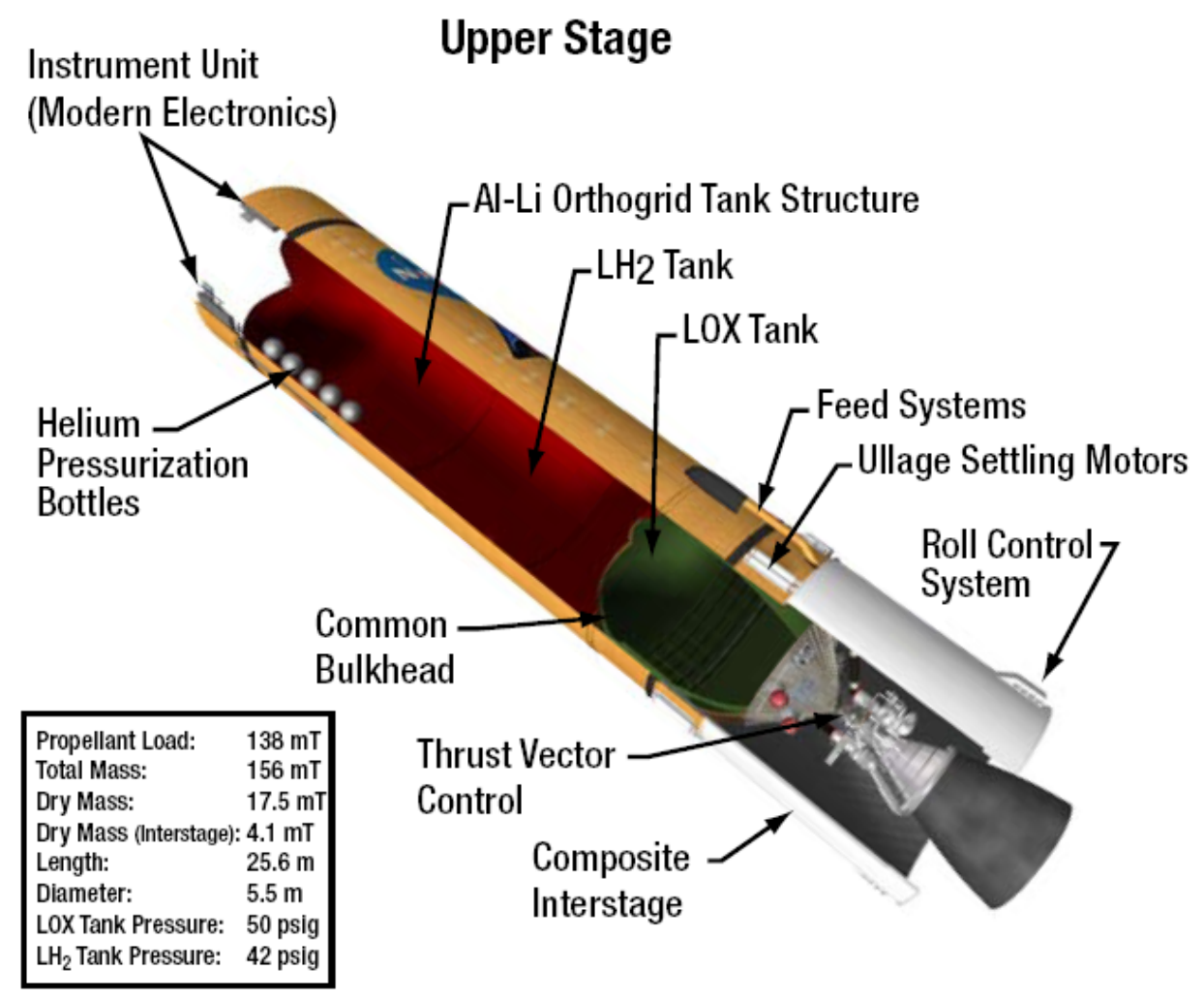

FIGURE 1. Depiction of the Upper Stage of the Ares 1 launch vehicle. The stage is fabricated predominantly from aluminum and aluminum-lithium alloys, joined by friction stir welding.

\section{FRICTION STIR WELDING}

In the FSW process, two abutted parent materials are plastically stirred together, without being melted. Invented by The Welding Institute in 1991 [1], the approach has found much interest because it can produce a stronger joint than fusion welding, and can be employed in metals which do not join well using fusion techniques. One form of FSW used on the Ares 1 is a self-reacting FSW, depicted in Fig. 2. Friction to heat the metals to plasticity is provided by a rotating pin, passing through the materials to be welded. Forging force is provided by pinching the plates between two shoulder pieces, rotating with the pin. The rotating pin/shoulders combination is moved along the abutted materials, leaving the stirred material in its path.

\section{BASELINE PAUT APPROACH FOR ARES 1}

The baseline approach for inspecting Ares 1 FSW using PAUT is schematically depicted in Fig. 3. A linear 64-element $10 \mathrm{MHz}$ array is mounted on a water-filled wedge, at an angle selected to yield approximately 45 degree refracted shear waves in the material. An active aperture of 16 elements is electronically scanned along the array to produce 49 parallel scan lines across the weld. The weld bead is fully inspected by the direct and first reflected sound paths, and most is covered by both legs. A focal point is set at the midplane of the plates. Instrument sensitivity is calibrated using a 0.030 " diameter side-drilled hole located at the center of the weld bead. 


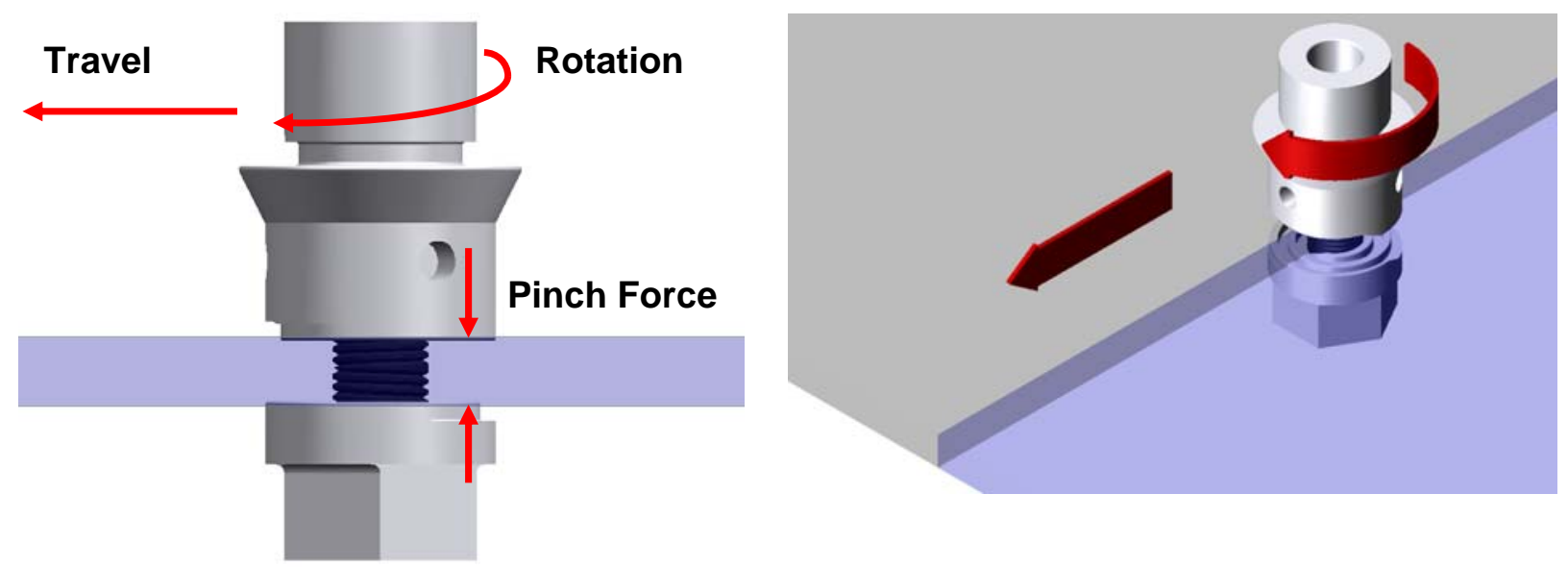

FIGURE 2. A depiction of a self-reacting friction stir weld of a butt joint.

\section{RESIDUAL OXIDE DISCONTINUITY (ROD)}

Aluminum naturally forms a layer of oxide on its surface by reacting with oxygen in the air. The abutting surfaces are carefully cleaned before welding to minimize the amount of oxide to potentially be entrained in the weld. Normally, the friction stir process breaks up the oxide into small particles and disperses them in the weld bead. If the oxide particles are not sufficiently dispersed, and remain in close proximity, they may form a thin layer representing a discontinuity in metallic properties. This is called residual oxide discontinuity, kissing bond, and other things.

Two micrographs of ROD are presented in Fig. 4. In these examples, the oxides are observed as broken, wavy lines, only a few microns in thickness. The gross characteristics of ROD are depicted in four examples in Fig. 5. The entire weld bead is shown in these

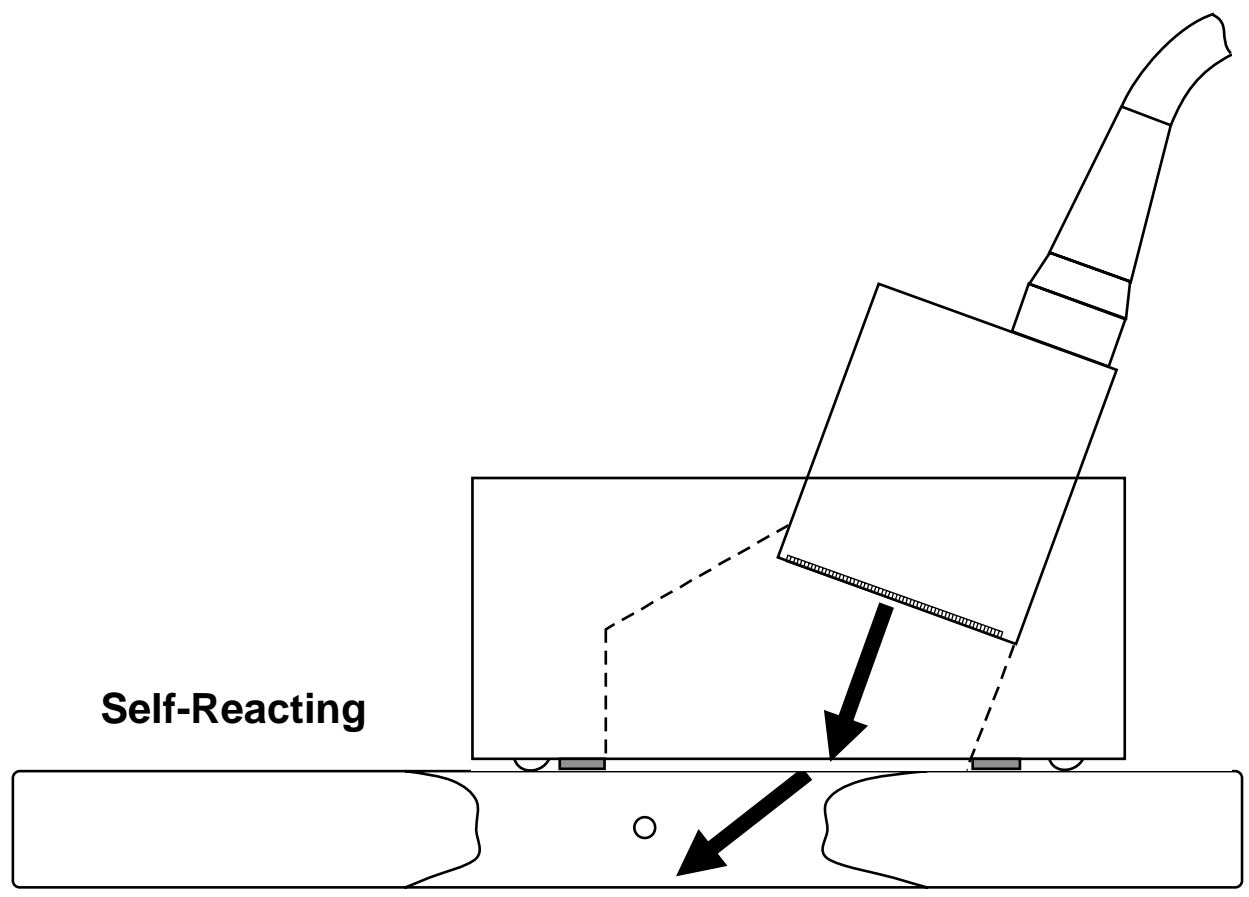

FIGURE 3. Depiction of the baseline PAUT approach for FSW for the Ares 1 Upper Stage. 

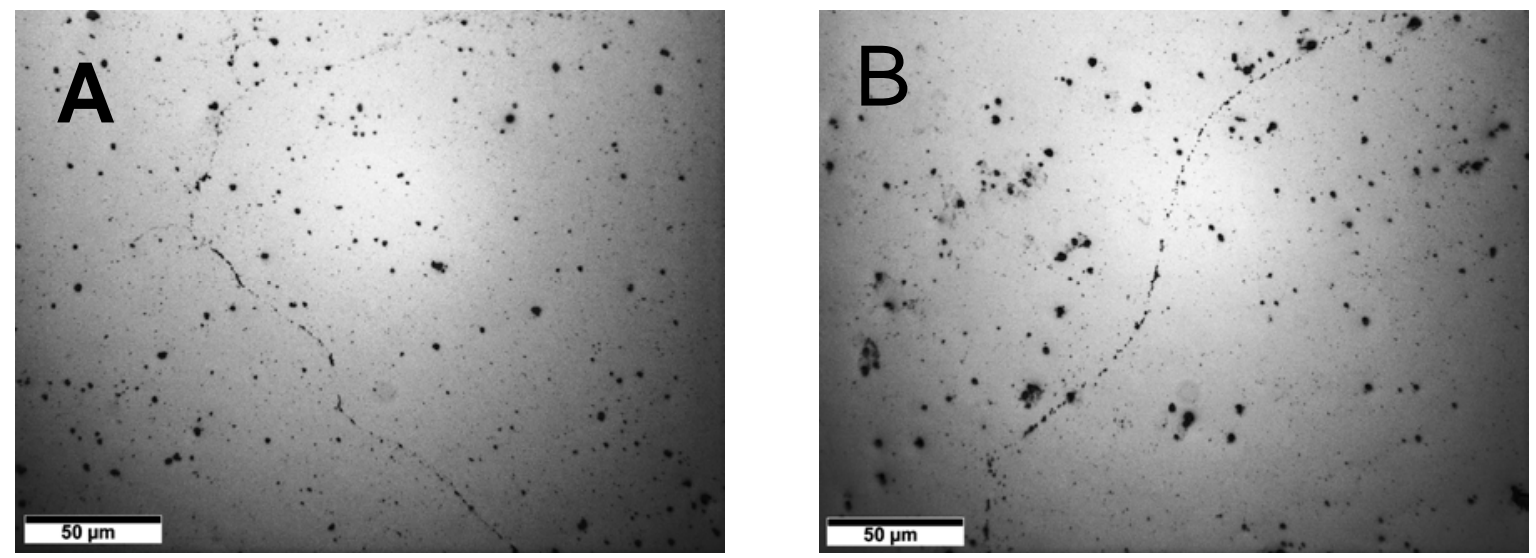

FIGURE 4. Two examples of ROD in aluminum FSW. The scale is given by bars of 50 micron length.

examples. The stirred boundary between the two parent materials is highlighted by wavy white lines. ROD, if it occurs, is most likely to be found along these wavy boundaries. White arrows indicate the propagation direction of 45 degree shear waves in the first and second legs of a PAUT inspection.

The examples shown in Figs. 4-5 illustrate the physical characteristics of ROD. When it occurs, ROD comprises a broken layer, a few microns in thickness, non-planar, with very little presentation at normal incidence to the interrogating shear waves. All of these physical factors make ROD a difficult target.

\section{APPROACH}

An approach to establish an upper bound on the potential detectability was to model ROD as an idealized planar layer of aluminum oxide, oriented for normal incidence of the incoming 45-degree shear waves. Theory is readily available for calculating the reflection coefficient of sound from a layer and from a boundary between two materials. In order to relate
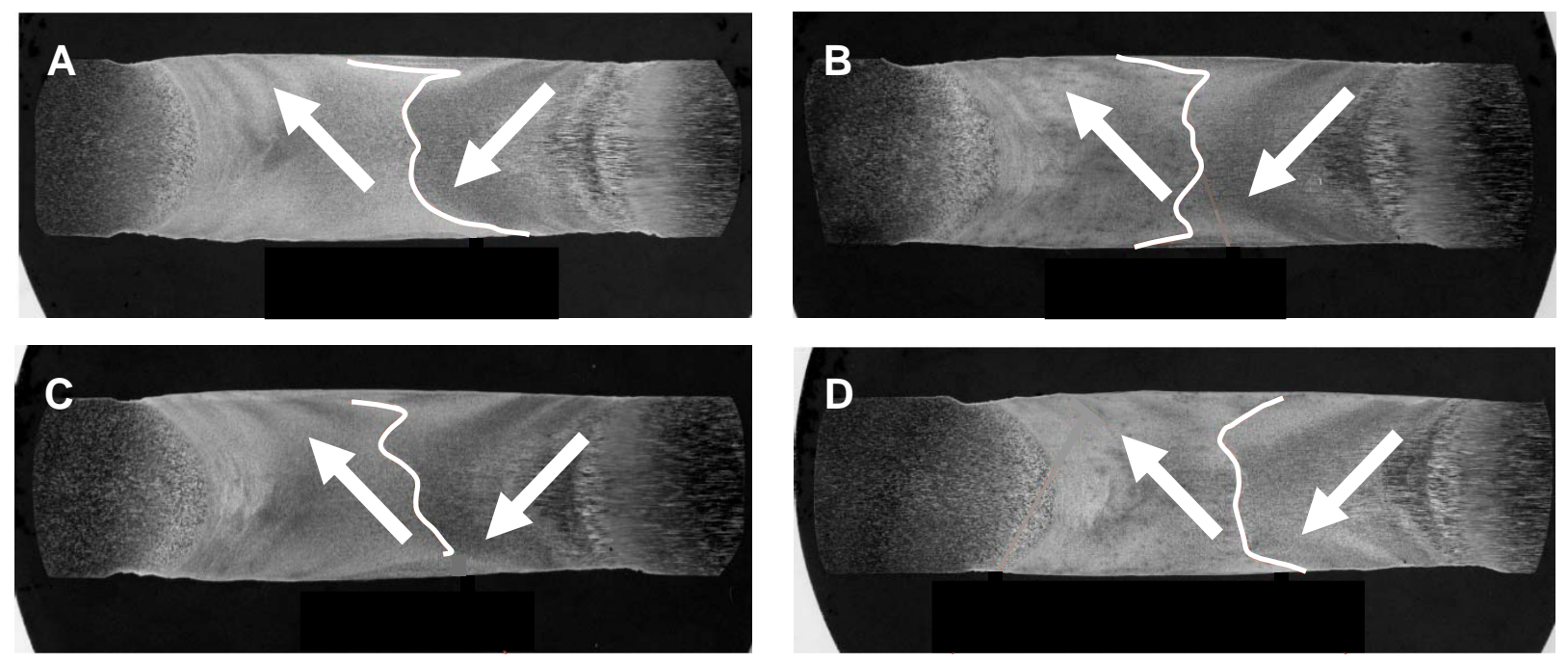

FIGURE 5. Four examples showing the gross variation of sites for potential ROD. The boundary between the two metals, where ROD is most likely to be found, is indicated by a white line. PAUT 45-degree shear wave directions are indicated by arrows. 
the model to the experimental situation, reference measurements were made of the scattering amplitude from the FSW grains, which represents the effective noise floor for a PAUT inspection, and of the amplitude of a reflection from an interface between the aluminum and water. By expressing the model results and the grain scattering results in terms of $\mathrm{dB}$ relative to a planar $\mathrm{Al}$-water reflection, the range of potentially detectable ROD can be established.

\section{THEORY}

The geometry of the idealized oxide layer is presented in Fig. 6A. A planar layer of thickness $L_{\text {layer }}$ of aluminum oxide, of acoustic impedance $z_{\text {oxide }}$ and shear velocity $v_{\text {oxide }}$, is embedded in aluminum, with acoustic impedance $z_{A l}$. The layer is oriented at 45 degrees so as to be normal to the incoming 45-degree shear waves. The power reflection coefficient from the layer is given by [2]:

$$
\Gamma_{\text {layer }}=\left|\frac{z_{A l}-z_{\text {layer }}}{z_{A l}+z_{\text {layer }}}\right|^{2}
$$

where

$$
z_{\text {layer }}=z_{\text {oxide }}\left(\frac{z_{A l}+i z_{\text {oxide }} \tan \left(2 \pi f L_{\text {layer }} / v_{\text {oxide }}\right)}{z_{\text {oxide }}+i z_{A l} \tan \left(2 \pi f L_{\text {layer }} / v_{\text {oxide }}\right)}\right) \text {. }
$$

The power reflection coefficient from a water/aluminum boundary oriented normal to the incoming 45-degree shear waves, depicted in Fig. 6B, is given by:

$$
\Gamma_{\text {boundary }}=\left|\frac{z_{A l}-z_{\mathrm{H}_{2} \mathrm{O}}}{z_{A l}+z_{\mathrm{H}_{2} \mathrm{O}}}\right|^{2} \text {. }
$$

Expressing the ratio of $\mathrm{t}$

he layer reflection to the boundary reflection in logarithmic $(\mathrm{dB})$ form yields:

$$
\Gamma_{\text {layer }}[d B]=10 \log _{10}\left(\frac{\Gamma_{\text {layer }}}{\Gamma_{\text {boundary }}}\right) .
$$

The reflection coefficient was calculated using Eqs. (1)-(4) for layer thickness from 0.2 microns to 50 microns. The results obtained for ultrasonic frequencies $5 \mathrm{MHz}, 10 \mathrm{MHz}$ and $20 \mathrm{MHz}$ are plotted in Fig. 7. The density and sound velocity values used for the calculations are also shown in Fig. 7. For oxide layers 10 microns thick or more, there is substantial reflection obtained. Below 5-10 microns, as the layer thickness decreases, the reflection coefficient falls rapidly towards zero.

\section{EXPERIMENT}

The measurement geometry is depicted in Fig. 8. Four friction stir welds were cut at 45 degrees through the weld bead, and the average amplitude, $A_{\text {boundary }}$, of the reflection from the water/aluminum boundary was measured at 16 locations. The gain of the system 


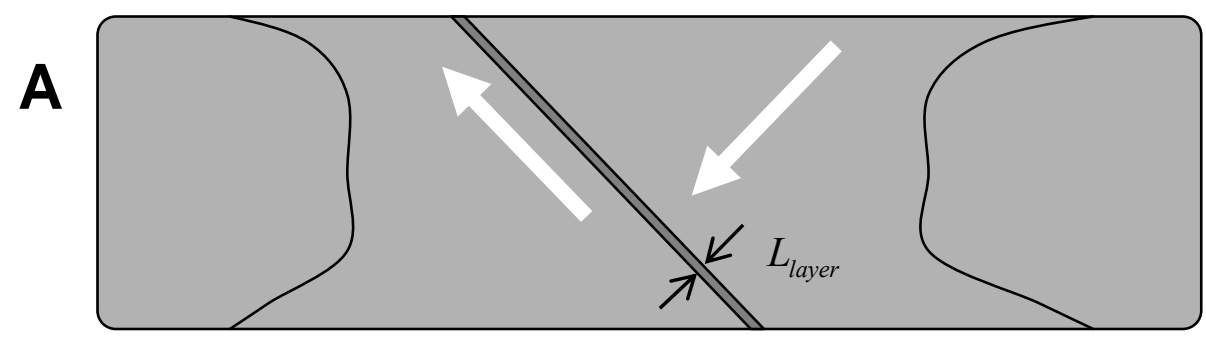

B

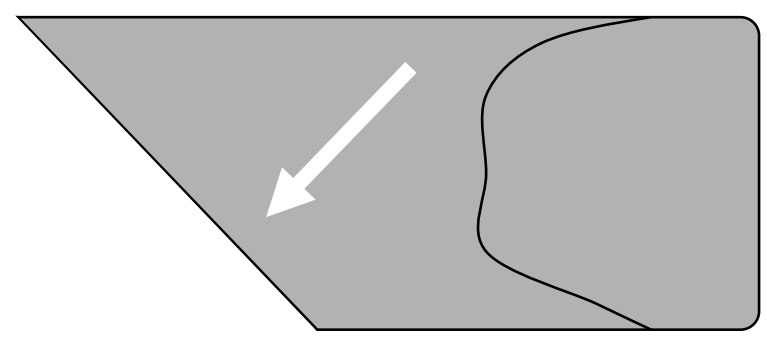

FIGURE 6. A) Sketch of an idealized oxide layer embedded in aluminum. B) Sketch of a water/aluminum boundary.

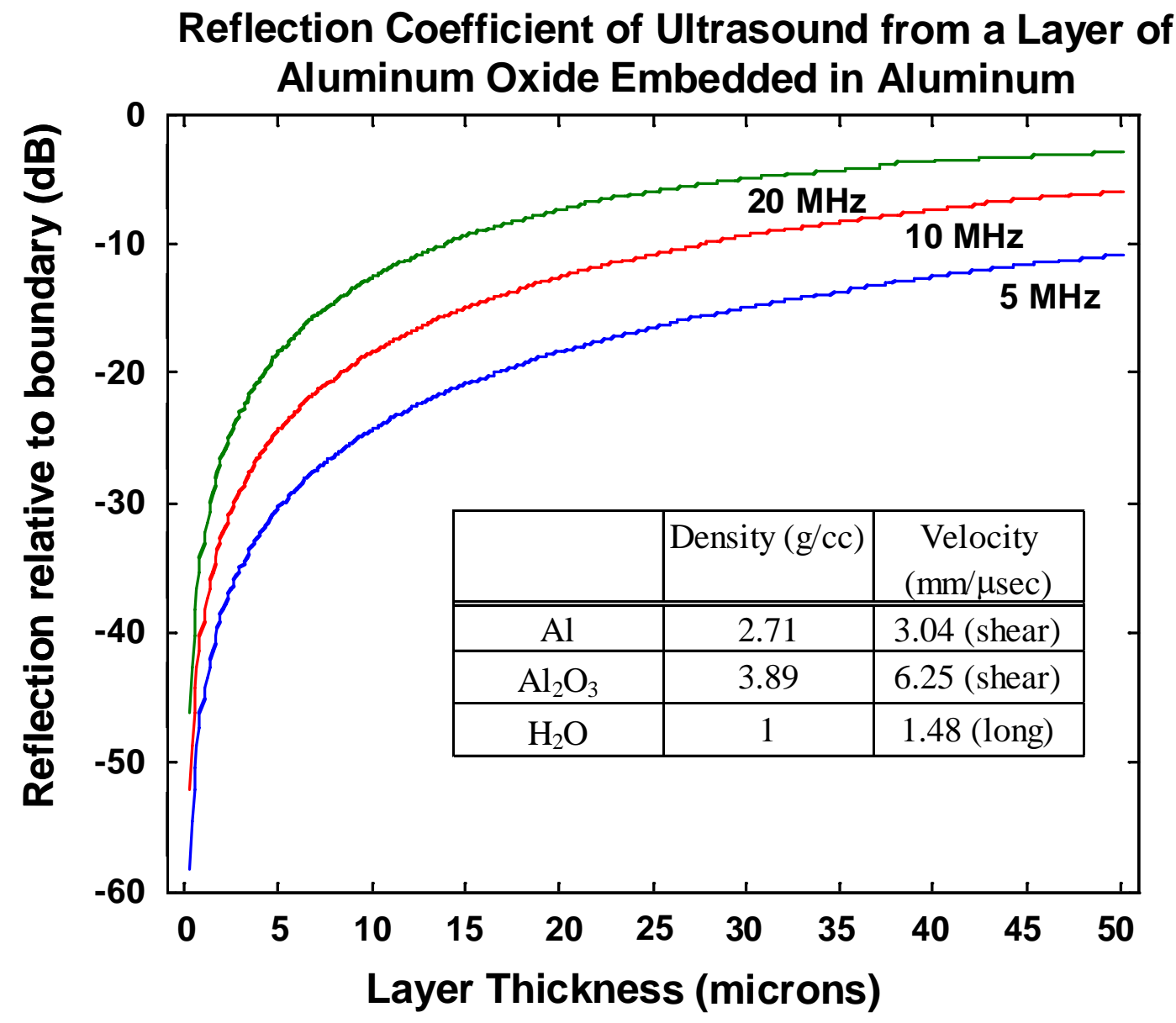

FIGURE 7. Calculated reflection coefficient of an idealized oxide layer embedded in aluminum, expressed as $\mathrm{dB}$ relative to the reflection from a water/aluminum boundary. The values used in the computation are shown. 


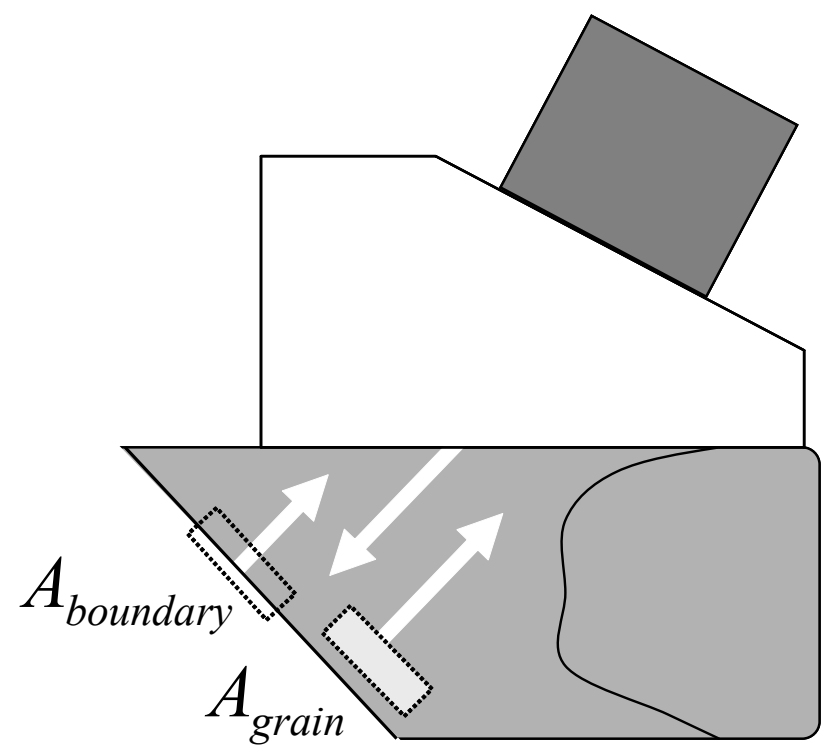

FIGURE 8. Sketch of the measurement geometry for determining the grain scattering amplitude relative to a water/aluminum boundary.

was then increased, to permit the measurement of the average amplitude, $A_{\text {grain }}$, of the scattering from the metal grains near the water/aluminum boundary. The relative reflection coefficient was then computed according to:

$$
\Gamma_{\text {grain }}[d B]=20 \log _{10}\left(\frac{A_{\text {grain }}}{A_{\text {boundary }}}\right) .
$$

The results for measurements at $10 \mathrm{MHz}$ are plotted in Fig. 9. The average of the $\mathrm{dB}$ values was found to be approximately $-54 \mathrm{~dB}$.

\section{Grain Scattering Amplitude Expressed Relative to Boundary Reflection}

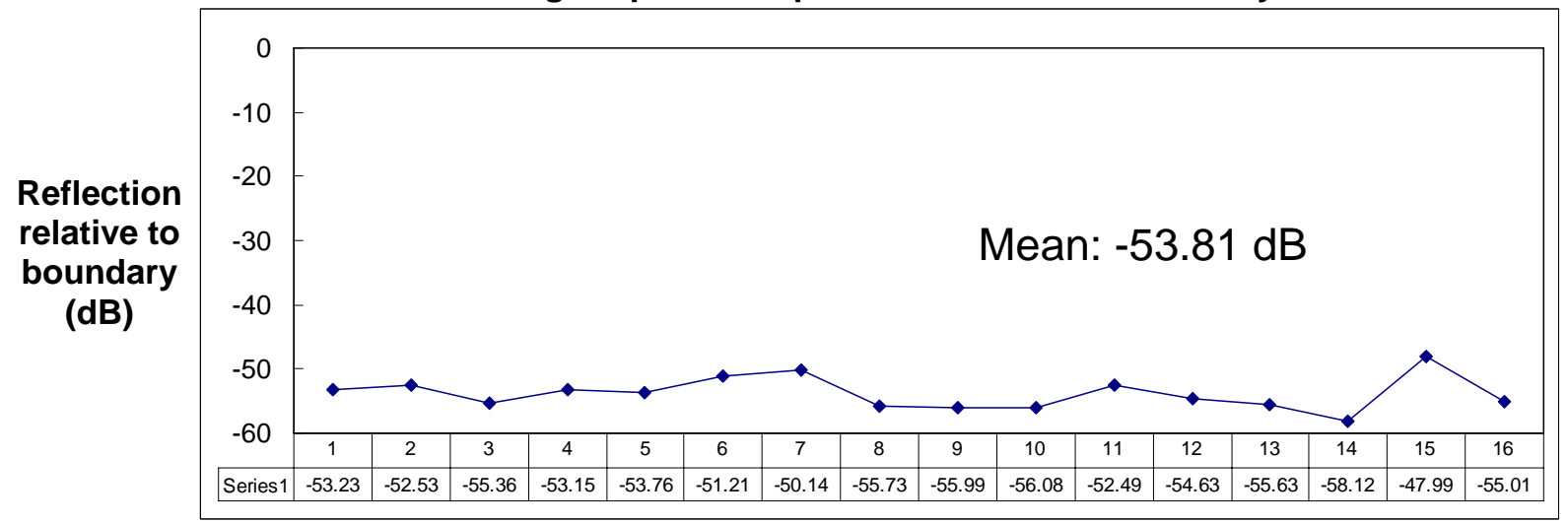

FIGURE 9. Plot of 16 measurements of grain scattering amplitude relative to the reflection from a nearby water/aluminum boundary 


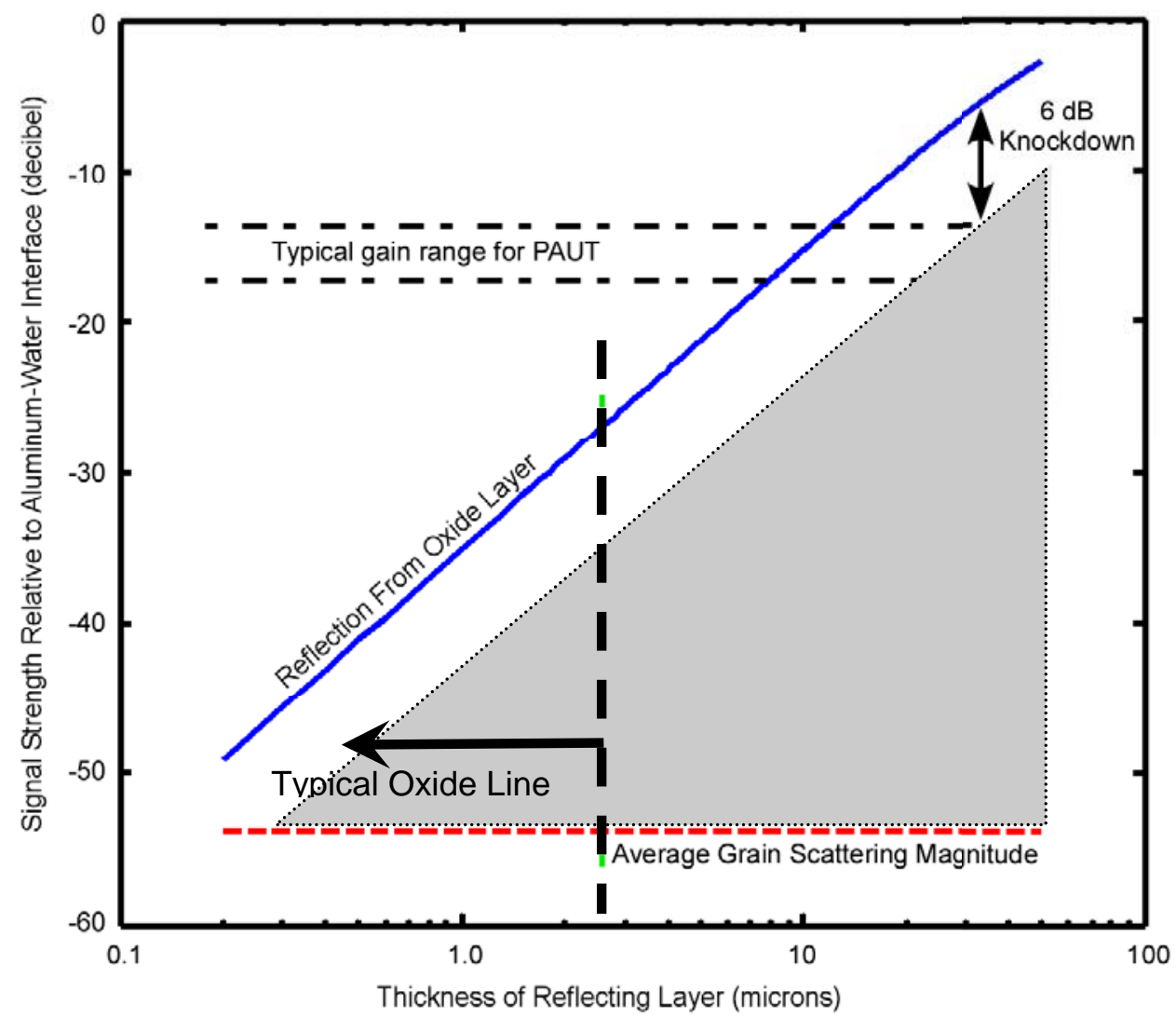

FIGURE 10. A plot summarizing the data. The theoretical region of potential detectability for naturallyoccurring ROD is below the solid data curve, above the grain scattering (noise) level, and at naturallyoccurring thicknesses (near and to the left of the vertical dashed line).

\section{SUMMARY}

Fig. 10 summarizes the results. The $10 \mathrm{MHz}$ data from Fig. 7 are plotted with thickness on a logarithmic scale. The "noise floor" represented by the grain scattering is a dashed horizontal line at $-54 \mathrm{~dB}$. A vertical dashed line at 2.5 microns represents the typical layer thickness observed microscopically in ROD specimens. A grayed region is identified, applying a modest $6 \mathrm{~dB}$ knockdown of signal due to non-idealized nature of naturally-occurring ROD. The region of theoretically potential detectability of ROD falls within the gray area, which is below the solid theory curve and inside the two dashed lines. For reference, the typical range of gains employed by MSFC for inspecting FSW is indicated between 15-18 dB. These results suggest that gains of $40 \mathrm{~dB}$ or more would be required to detect naturally-occurring ROD in aluminum FSW.

\section{REFERENCES}

1. W.M. Thomas, E.D. Nicholas, J.C. Needham, M.G. Murch, P. Temple-Smith, and C.J. Dawes, Friction-stir butt welding, GB Patent No. 9125978.8, International Patent No. PCT/GB92/02203, (1991).

2. L.M. Brekhovskikh, Waves in Layered Media, 2nd ed., trans. by R.T. Beyer, Academic Press, New York, (1980), p. 17. 
ADDRESSING THE LIMIT OF DETECTABILITY OF RESIDUAL OXIDE DISCONTINUITIES IN FRICTION STIR BUTT WELDS OF ALUMINUM

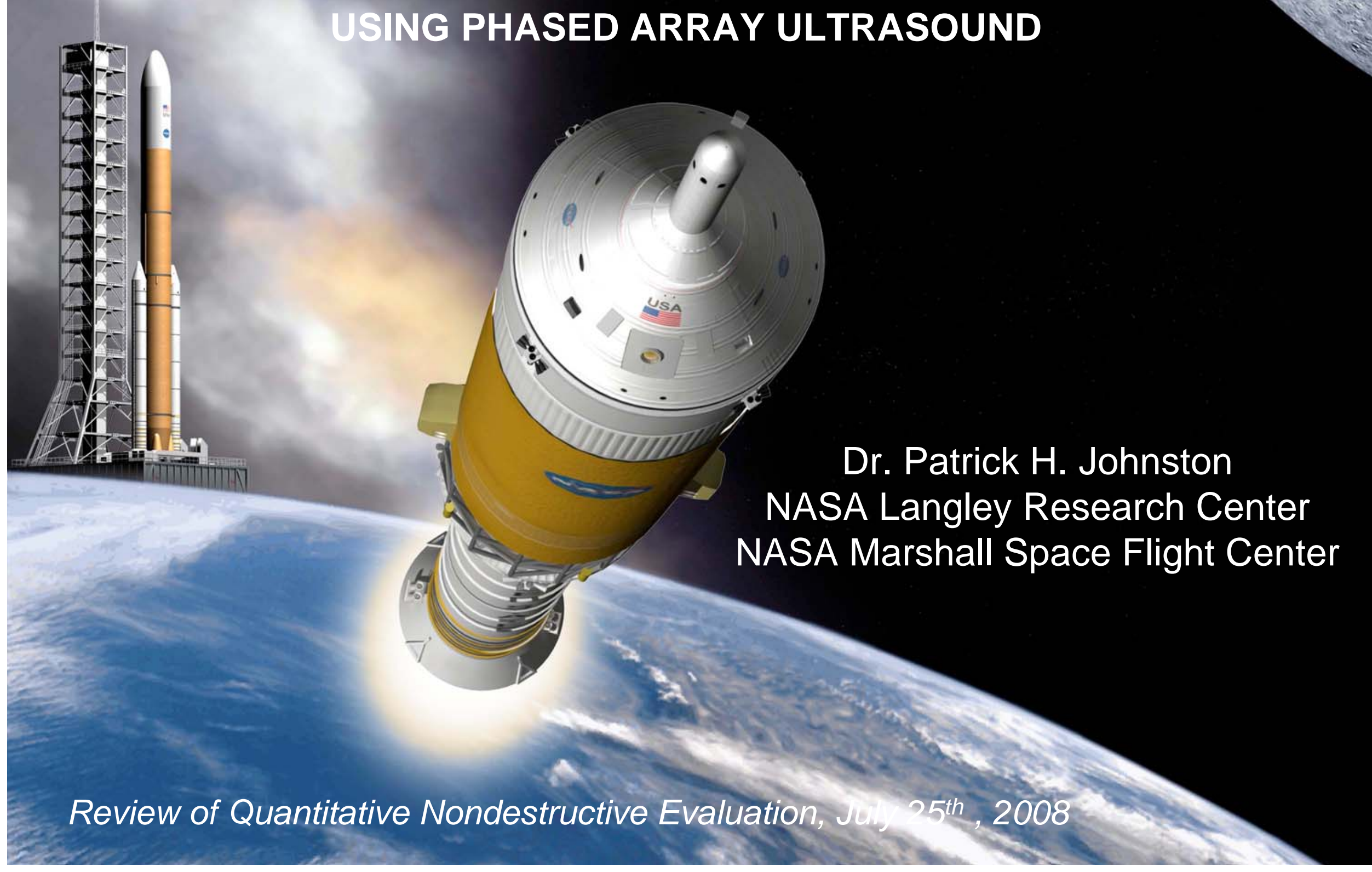




\section{OUTLINE}

Friction stir welding (FSW) for the Ares 1 Upper Stage

- Phased Array Ultrasonic Testing of FSW

$\checkmark$ Residual Oxide Discontinuity (ROD)

$\checkmark$ Approach

Theoretical part

- Experimental part

$\checkmark$ Results

$\checkmark$ Conclusion 


\section{ARES 1 Launch Vehicle}

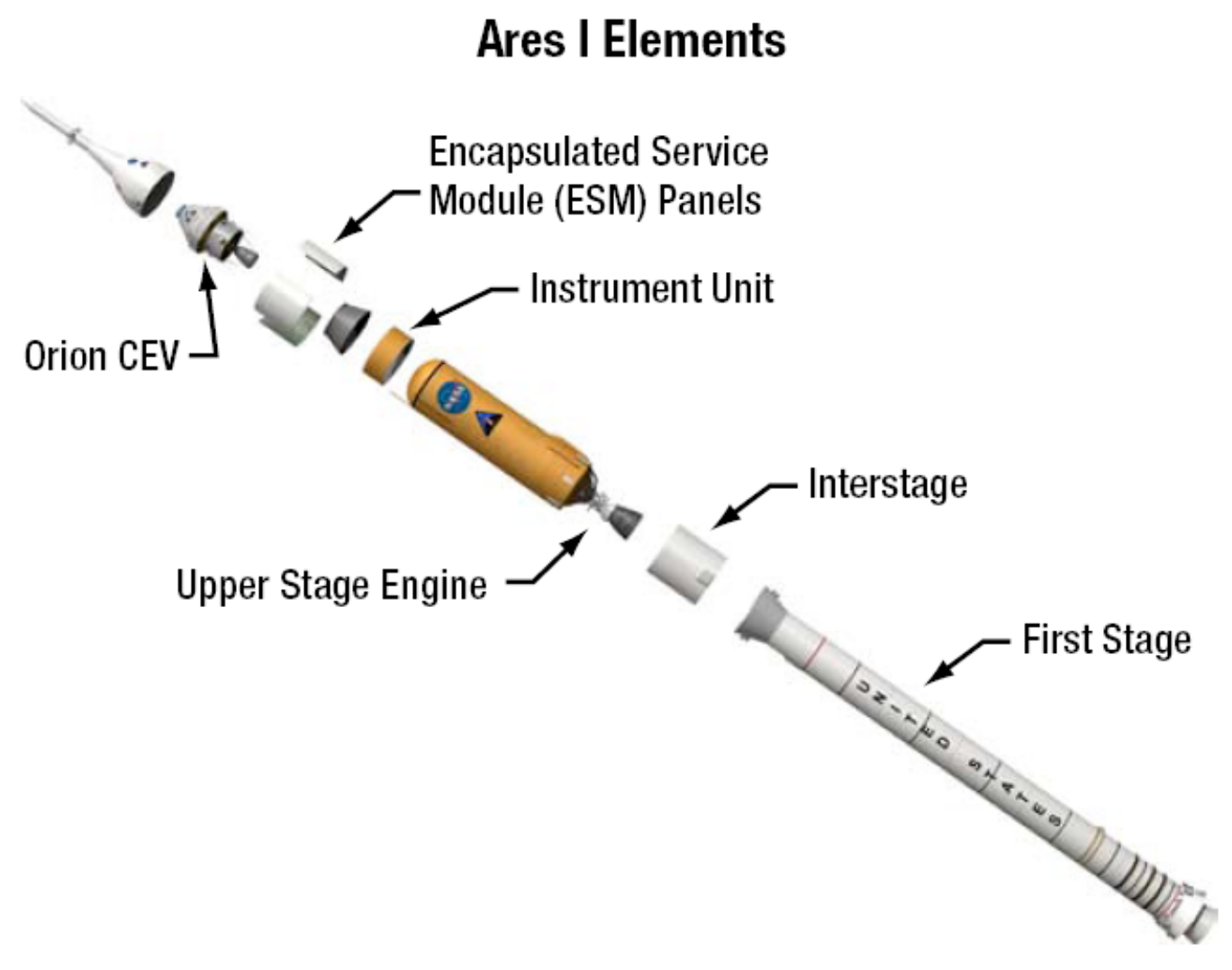




\section{ARES 1 Upper Stage}

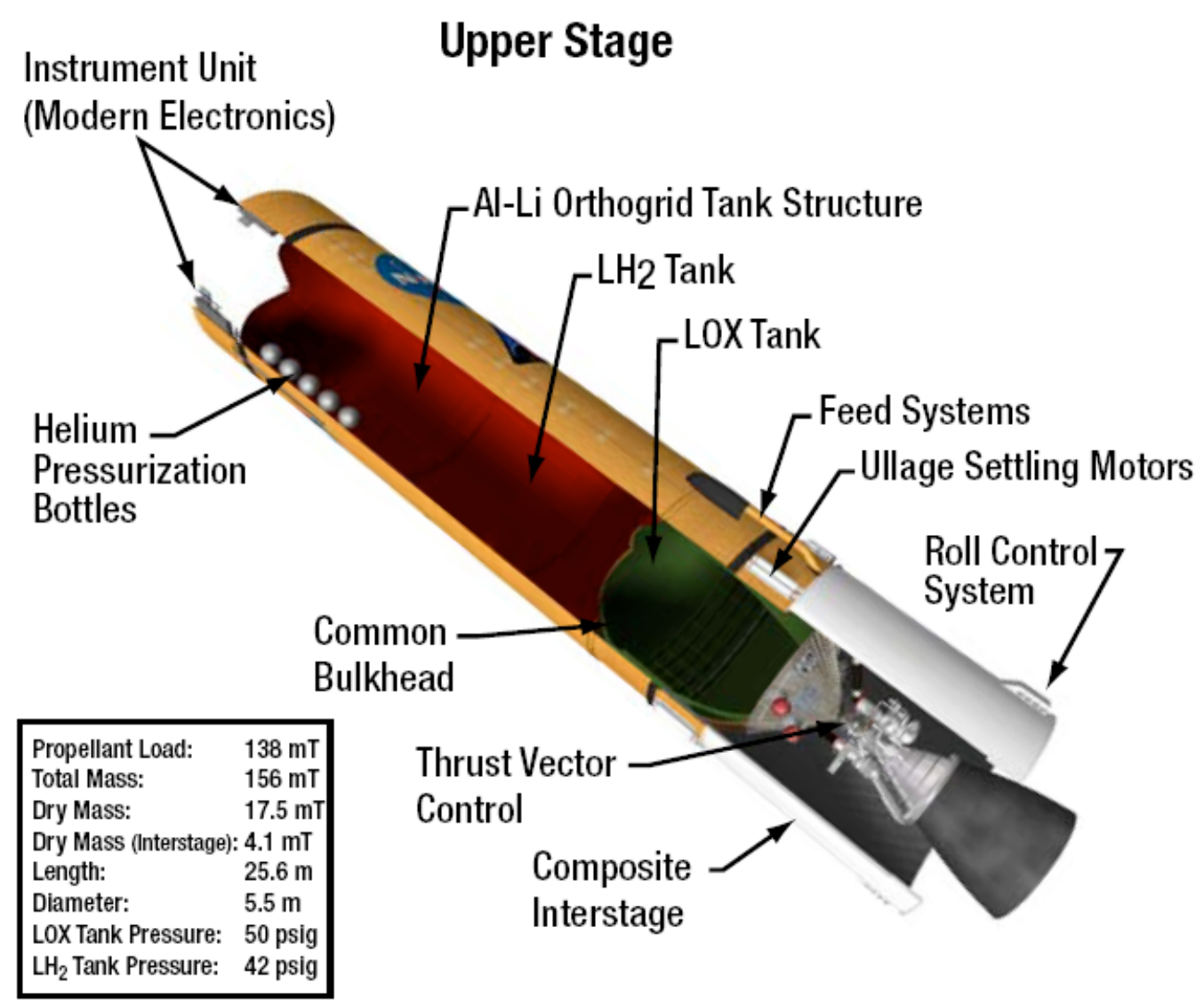

Most of the Upper Stage structure is made of aluminum alloys joined by friction stir welding 


\section{Friction Stir Welding}

- In friction stir welding (FSW) the two parent materials are plastically stirred, without melting, by a rotating pin tool

- Forging force is provided by shoulders of tool and backing anvil (conventional) or by cospinning shoulders on opposite sides of plates (self-reacting)
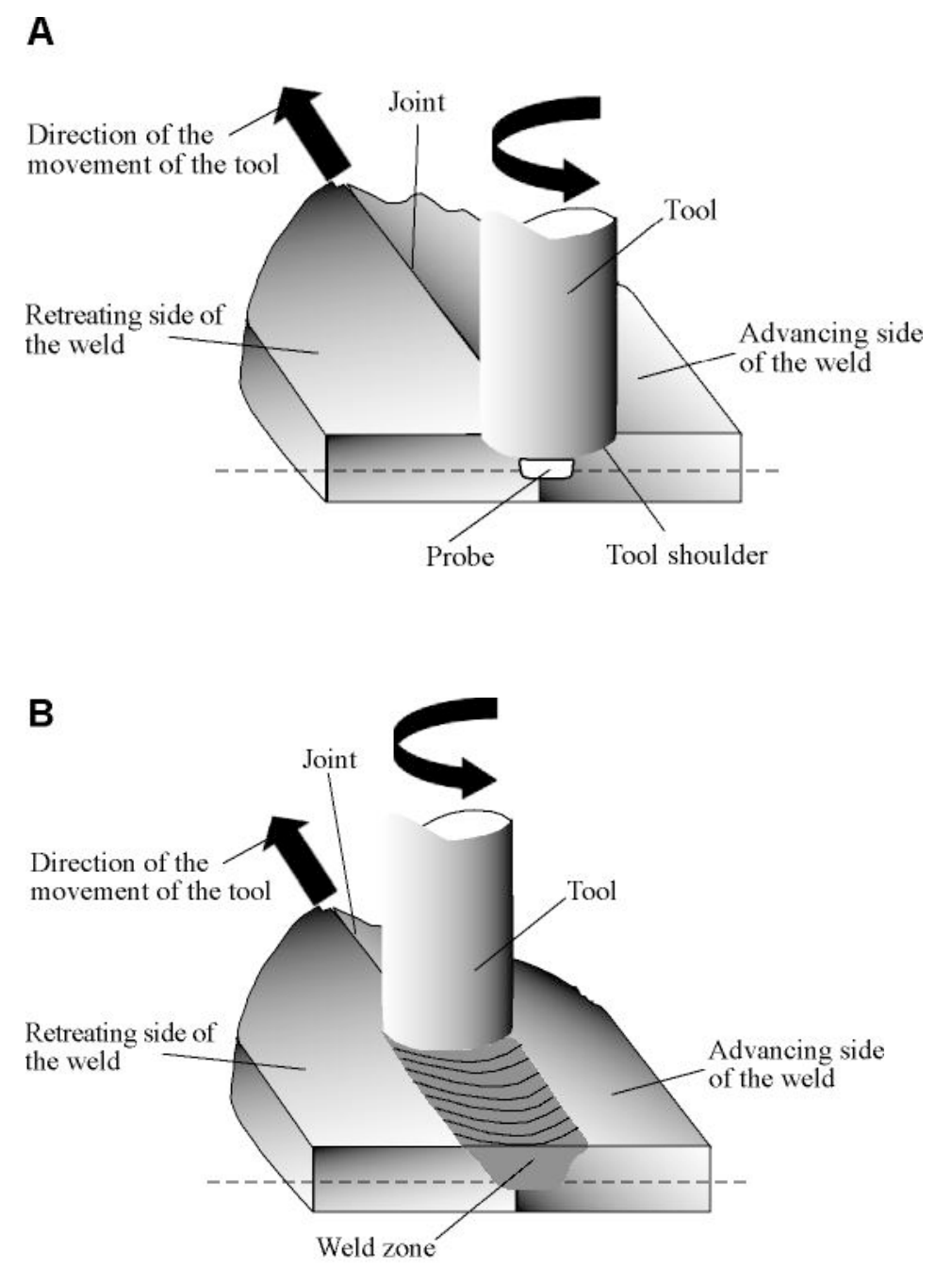

(Figures taken from http://en.wikipedia.org/wiki/Friction_stir_welding) 


\section{Phased Array Ultrasonic Testing (PAUT) of Friction Stir Weld Joint}

$\checkmark 10 \mathrm{MHz}$ 64-element array, mounted on wedge for nominally 45-degree refracted shear waves

$\checkmark$ 16-element aperture

- Focal depth at mid-plane

Linear scan over total array length

$\checkmark$ Most of weld bead covered by both first and second leg

^Set up on 0.030" dia SDH

Self-Reacting

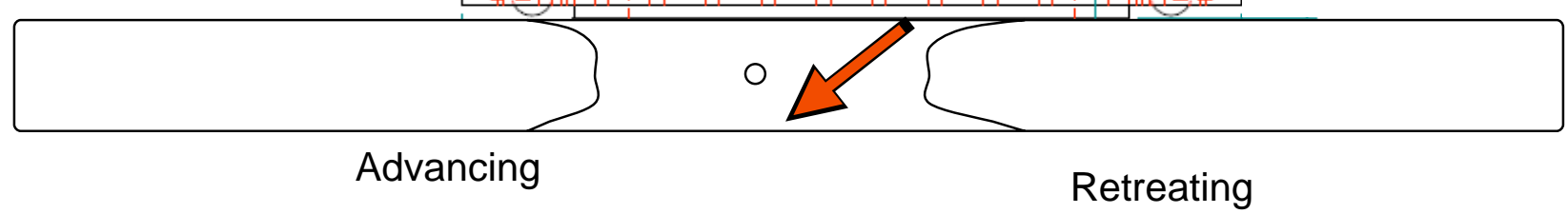




\section{Residual Oxide Discontinuity (ROD)}

$\checkmark$ Unwelded abutted aluminum surfaces have naturally-occurring oxide layers

These layers are scraped prior to welding to minimize the amount of oxide present

$\checkmark$ Properly welded joint breaks up the remaining oxide into dispersed separated particles

$\checkmark$ Residual Oxide Discontinuity (ROD) occurs if oxide particles remain in close proximity, presenting a surface of discontiuity (also known as unconsumed joint line remnant) 


\section{ROD Microscopically}

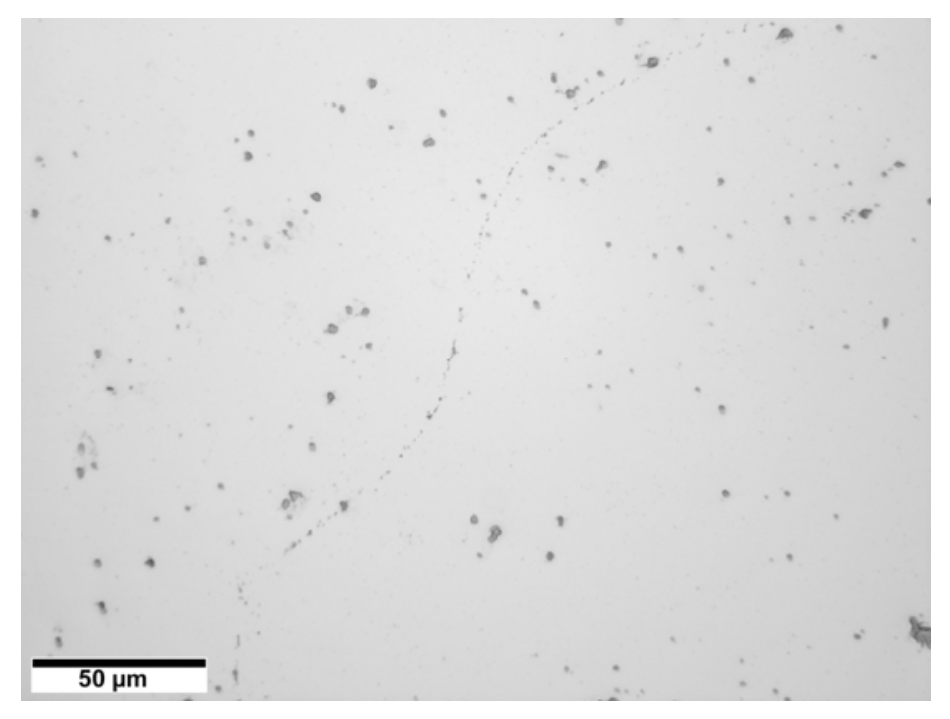

- ROD appears in micrographs as thin lines of oxide

- Thickness of line is typically no more than a few microns

- Oxide lines are broken, discontinuous 


\section{Gross Shape of ROD}
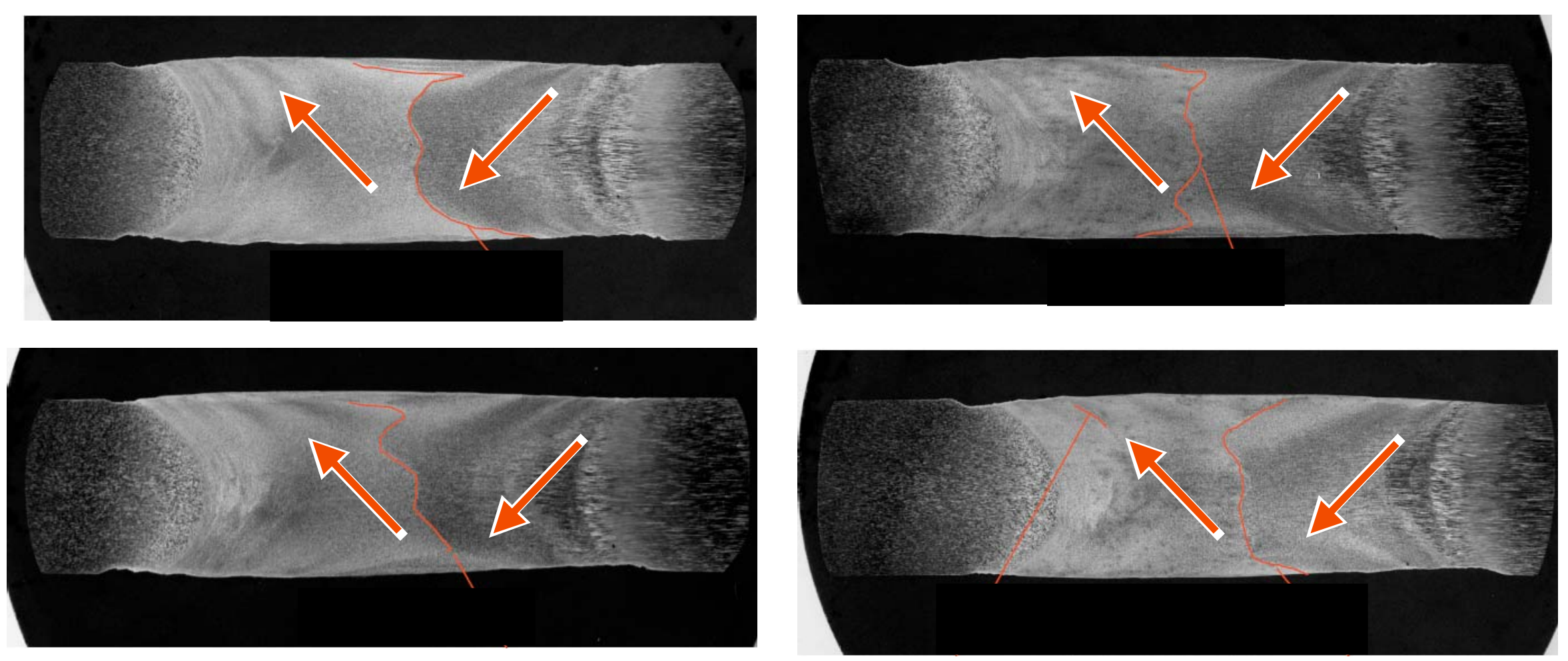

- ROD mostly occurs on boundary between two parent metals

- Stirred boundary is smeared into irregular shape

- Little data exists on shape in direction of weld 


\section{ROD Problem}

- It has not yet been determined that ROD can be ruled out as a critical flaw type for Ares 1

So, detection of ROD remains a matter of concern

There are varying reports of success in detecting ROD

The present task is to place a theoretical upper bound on the detectability of ROD in aluminum friction stir welds 


\section{Approach}

- Theory exists for the reflection coefficient of ultrasound from a boundary and from a layer

- Approach was to model ROD as an idealized layer, perfectly flat, completely filled with aluminum oxide

- This represents an upper bound, because actual oxide layer is not continuous, is curved, is not fully packed with oxide, which all will reduce the effective reflection coefficient

- Connect this model with experiment by expressing the result relative to the reflection coefficient from an Al-water boundary, which can be measured

- Experimentally measure the reflection from Al-water boundary and the scattering from grains, which represents the practical noise floor

- Compare the results to determine a range of detectability for ROD 


\section{Model of Most-Detectable ROD}

$$
\begin{gathered}
\Gamma_{\text {layer }}=\left|\frac{z_{A l}-z_{\text {layer }}}{z_{A l}+z_{\text {layer }}}\right|^{2} \\
z_{\text {layer }}=z_{\text {oxide }}\left(\frac{z_{A l}+i z_{\text {oxide }} \tan \left(2 \pi f L_{\text {layer }} / v_{\text {oxide }}\right)}{z_{\text {oxide }}+i z_{A l} \tan \left(2 \pi f L_{\text {layer }} / v_{\text {oxide }}\right)}\right)
\end{gathered}
$$

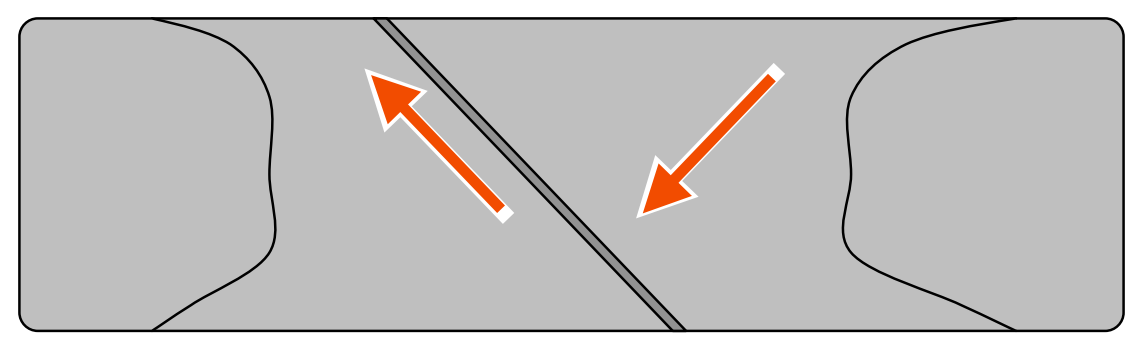

$$
\Gamma_{\text {boundary }}=\left|\frac{z_{A l}-z_{\mathrm{H}_{2} \mathrm{O}}}{z_{\mathrm{Al}}+z_{\mathrm{H}_{2} \mathrm{O}}}\right|^{2}
$$

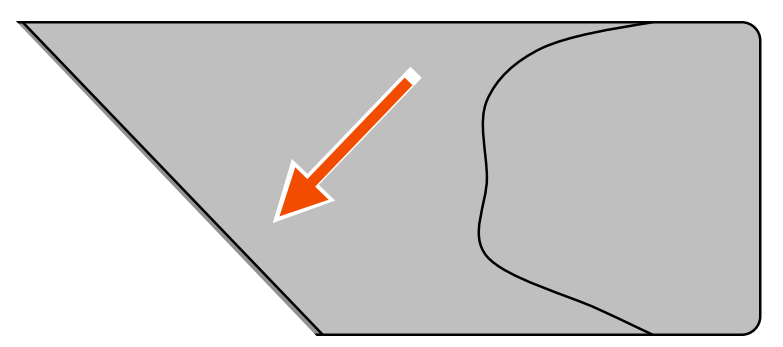

Expressed in $\mathrm{dB}: \quad \Gamma_{\text {layer }}[d B]=10 \log _{10}\left(\frac{\Gamma_{\text {layer }}}{\Gamma_{\text {boundary }}}\right)$ 


\section{Theory}

\begin{tabular}{|c|c|c|}
\hline & Density (g/cc) & $\begin{array}{c}\text { Shear Velocity } \\
(\mathrm{mm} / \mu \mathrm{sec})\end{array}$ \\
\hline \hline $\mathrm{Al}$ & 2.71 & 3.04 \\
\hline $\mathrm{Al}_{2} \mathrm{O}_{3}$ & 3.89 & 6.25 \\
\hline
\end{tabular}

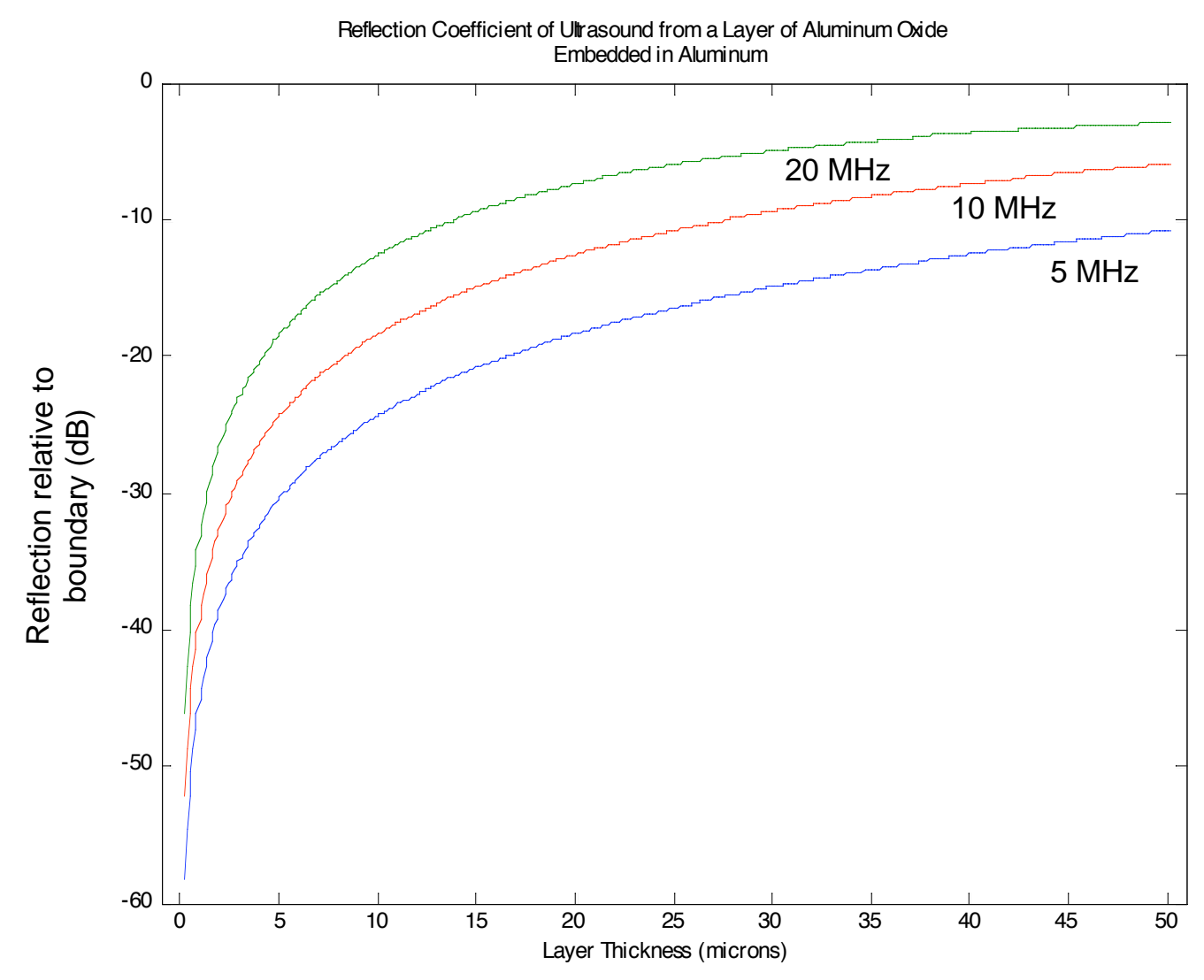




\section{Measurement of Grain Noise}

- Experimentally, measure the average amplitude of reflection from a surface cut at 45 degrees to allow reflection of 45 degree shear waves

- Increase the gain and measure the average amplitude of the scattering from the grains nearest the boundary

- Express the grain amplitude relative to the surface reflection in $\mathrm{dB}$

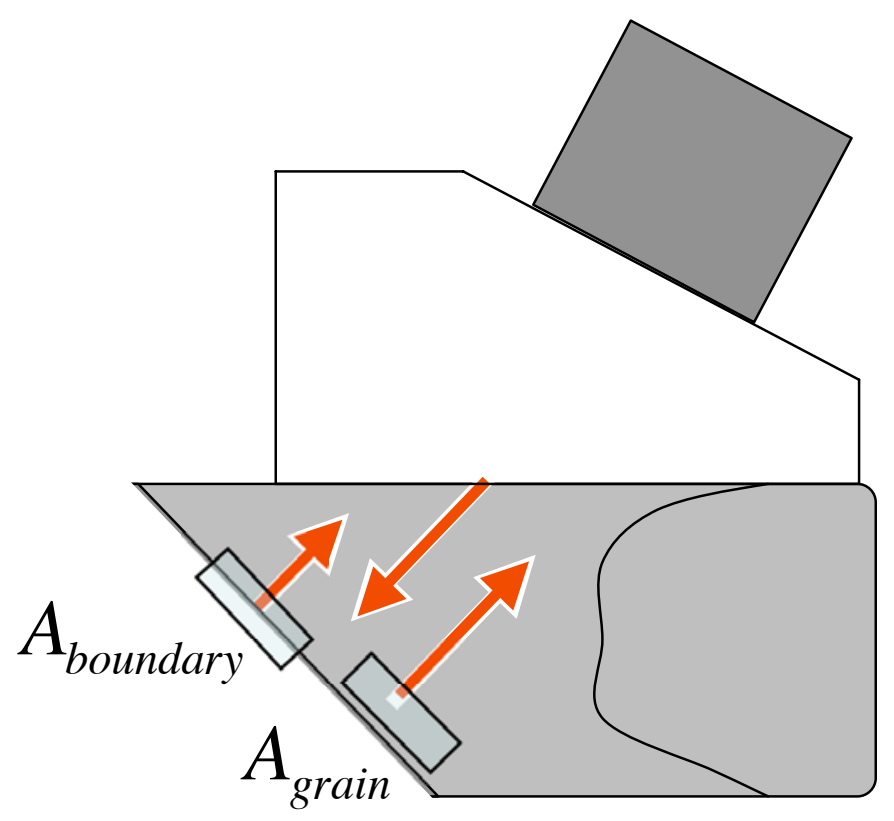

Expressed in dB: $\quad \Gamma_{\text {grain }}[d B]=20 \log _{10}\left(\frac{A_{\text {grain }}}{A_{\text {boundary }}}\right)$ 


\section{Measurement Results}

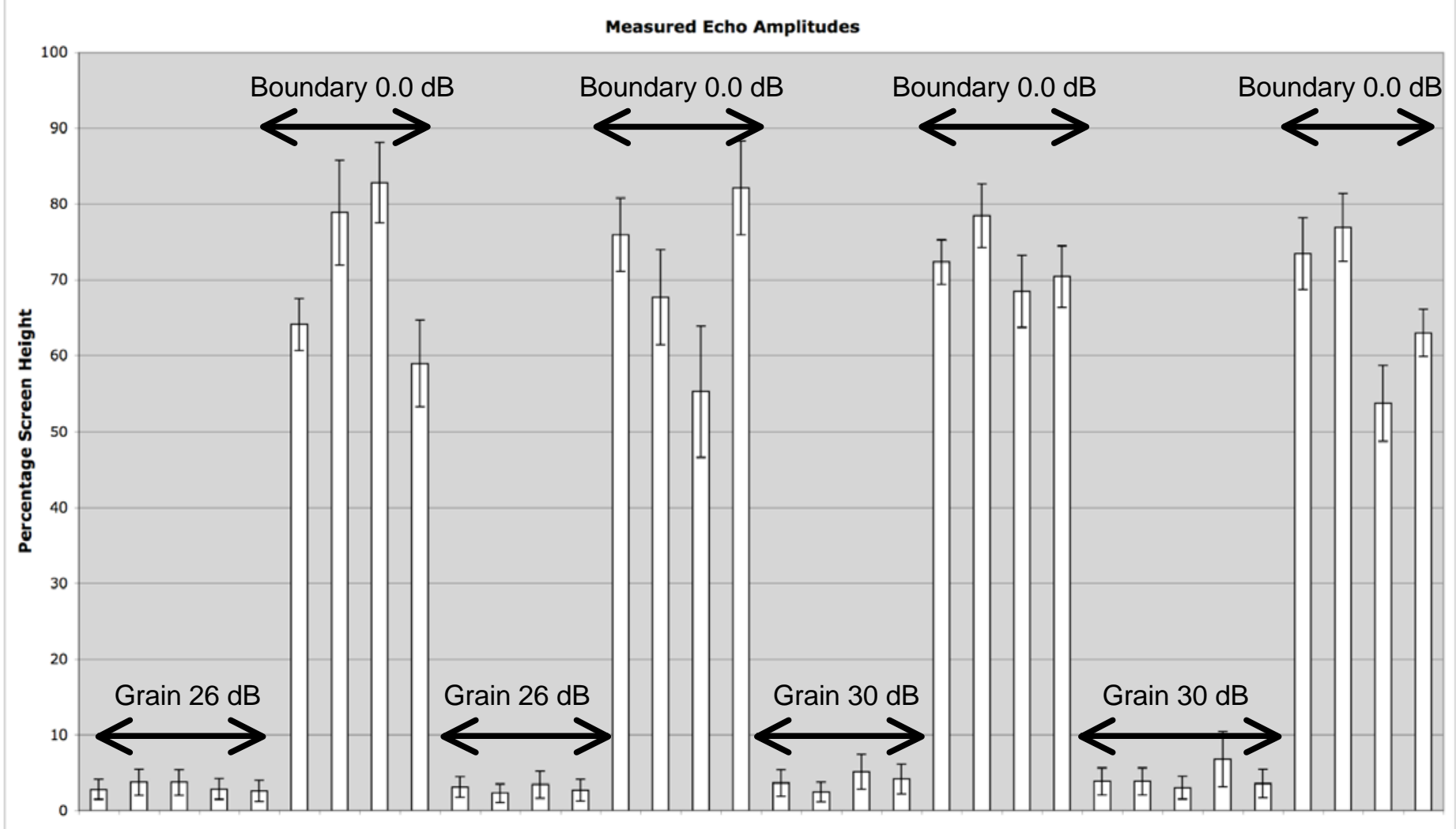

- Four welded panels were cut diagonally (45 deg) through weld nugget

- Average reflection from diagonal boundary was measured at $0.0 \mathrm{~dB}$ gain

- Gain was increased and average amplitude of grain scattering near boundary was measured 


\section{Measurement Results}

Grain Scattering Amplitude Expressed Relative to Boundary Reflection

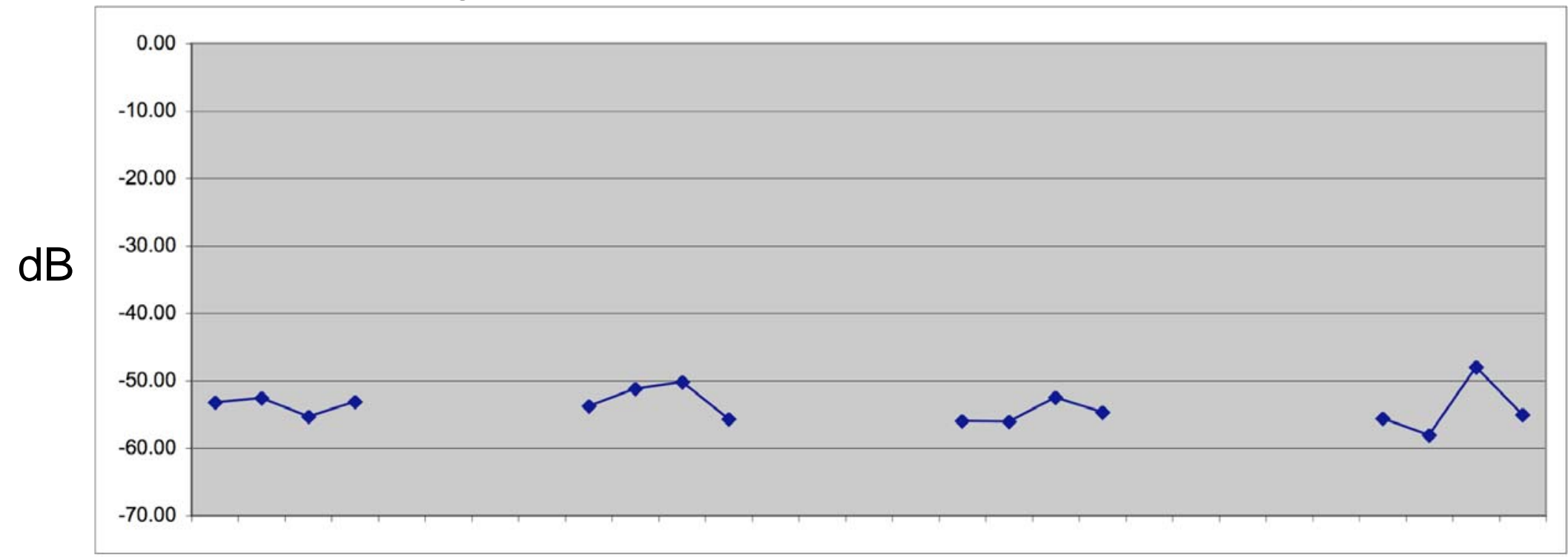

- Mean value of the grain scattering relative to the nearest boundary reflection expressed as $\mathrm{dB}$

- Mean of these values is $-53.81 \mathrm{~dB}$

- SD of these values is $2.56 \mathrm{~dB}$ 


\section{Detectability of ROD}

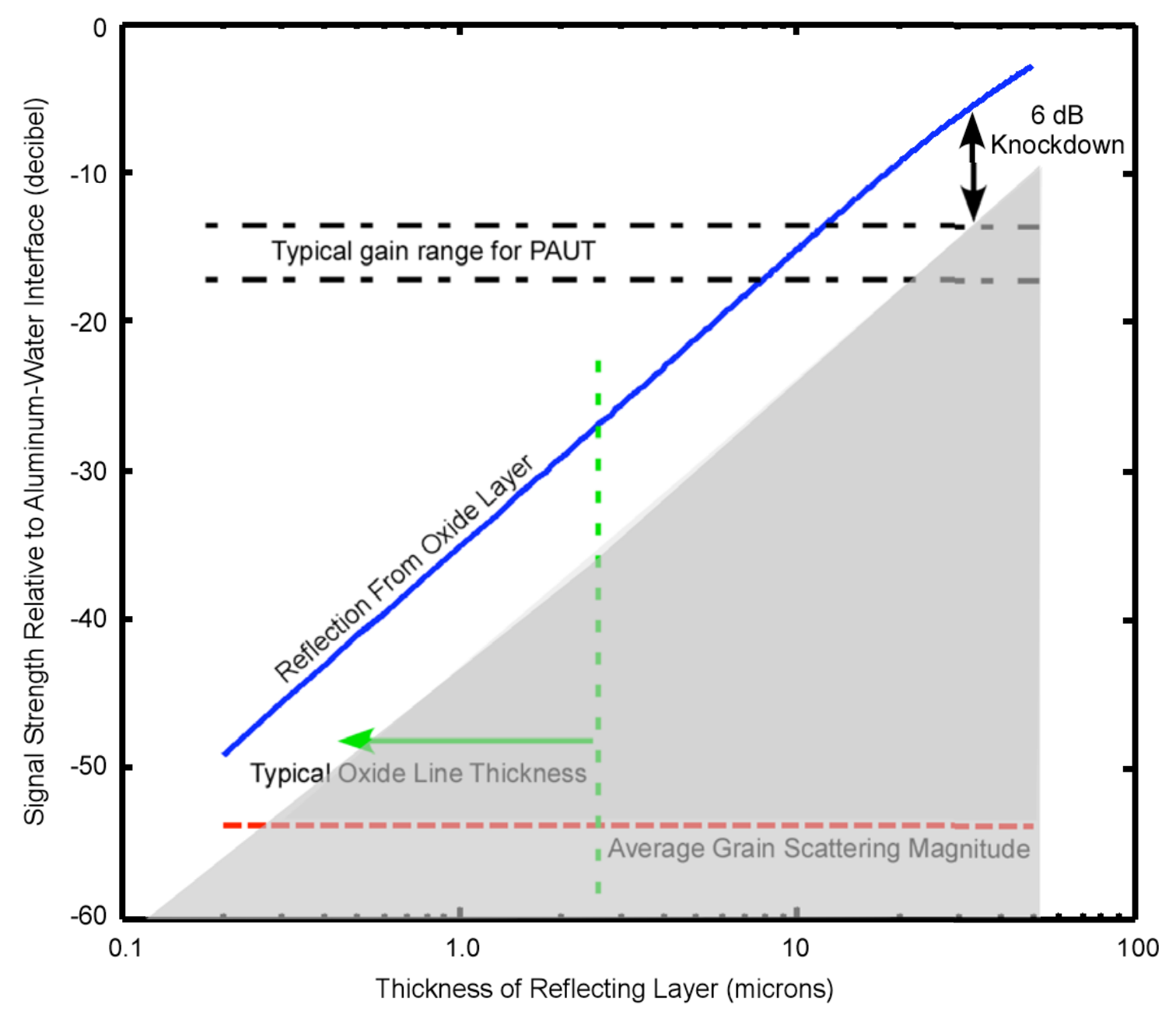




\section{Conclusion}

- Signal level from naturally-occurring ROD is predicted to be no more than $-40 \mathrm{~dB}$ relative to $\mathrm{Al}$-water reflection

- Currently, MSFC PAUT is performed using $15-20 \mathrm{~dB}$ gain

- Grain noise level at $-54 \mathrm{~dB}$ suggests that ROD may be detectable at higher gains ( $>40 \mathrm{~dB}$ )

- Propose to examine realistic ROD specimens and unnaturally thick (anodized) ROD specimens to confirm findings 